\title{
Geotropic Response at Various Angles of Inclination.
}

\author{
BY \\ FREDERICK C. NEWCOMBE. \\ University of Michigan.
}

A. Angle for Maximum Response of Primary Roots and Stems.

\section{INTRODUCTION.}

T $\mathrm{N}$ his fundamental work on the growth of roots, Sachs ${ }^{1}$ gives as the second of his three laws for the curvature of roots, that zones of equal development show various angles of curvature in the same time if the roots are placed at various angles with the vertical, and the curvature becomes the stronger the nearer the axis of the root is placed to the horizontal. Sachs does not give a very firm basis for this law, since he does not cite specific experiments from which the reader may judge the evidence. One finds, however, here and there a statement from which it is learned that Sachs laid seedlings at various angles of inclination, noting the latent period of curvature and the angles attained in given periods of time.

Bateson and F. Darwin ${ }^{2}$ tested the detached inflorescence-stalks of Plantago lanceolata and of Brassica olevacea by fastening them at various angles of inclination, allowing them so to remain for two hours, then releasing them and laying them horizontally under water so that their former right and left sides became the upper and lower. The angle of curvature after one hour was taken as an index of the strength of geotropic stimulation. The results agreed wholly with those of Sachs on roots, in finding the strongest curves in those stems which had been kept horizontal.

Czapek $^{3}$ next took up the problem with both roots and stems. His method consisted in tying the plant members to rods of wood or glass, or encasing them in closely-fitting glass tubes, and thus exposing them to gravitation stimulation for periods of three to six hours at temperatures of $17^{\circ}$ to $19^{\circ}$. The objects were then released and rotated on the klinostat for twenty-four hours, when the angles caused by the gravitation stimulation were measured and used as an index of relative intensity of response. In this way Czapek tested the roots of Lupinus, Vicia Faba, Phaseolus, Pisum and $Z e a$, the hypocotyl of Helianthus, and the sporangiophores of Phycomyces. As a general result the author states that the greatest angles were formed

1 Ueber das Wachsthum der Haupt- und Nebenwurzeln. Arbeit. bot. Inst. Würzb., i, I873, p. 454 .

2 'A Method of Studying Geotropism.' Ann. of Bot., ii, I888, p. 65.

${ }^{3}$ Untersuchung iiber Geotropismus. Jahrb. f. wiss. Bot., xxvii, 1895, p. 283.

[Annals of Botany, Vo1. XIX. No. LXXIV. April, 1905.] 
when the plant member was exposed to the gravitation stimulus at I $35^{\circ}$ from the position of normal equilibrium. Czapek attempted to use Sachs' latent period method also for measuring relative geotropic response, but found the curves beginning in approximately the same time at all angles of inclination between $20^{\circ}$ and $160^{\circ}$ from the position of stable equilibrium.

Stone $^{1}$, in a very brief report of work with the roots of Vicia Faba and stems of grass, found the horizontal position to be the one of greatest response. He used dynamometers to measure the force of bending, measured the angles attained at different inclinations of plant axis, and compared the after-effect curvatures.

A moment's reflection over the results recorded in the foregoing abstracts of investigations will show one that the subject treated is left in a very unsatisfactory condition. In the first place, if it is conceded that a representative number of roots has been tested, the number of species of stems used is far too small. The hypocotyl of Helianthus, the stem of some grass, and the scapes of the cabbage and plantain alone have been tested. In the second place, the method employed to secure Czapek's results-the most extensive work of all-seems to be open to several serious objections. The forcible retention of roots in glass tubes may, for ought we know, bring in traumatic phenomena. More serious still seems to me to be the consideration, the possibility of which must be admitted, that a weaker stimulus may accomplish as much as a stronger one, provided the period of operation is long enough. That is to say, Czapek forced his roots to lie at their various angles of inclination for three to six hours, a period far exceeding their latent period. It is easily conceivable that the gravitation-stimulus might in such a period effect the same result in roots stimulated at $90^{\circ}$ and at $\mathrm{I} 35^{\circ}$ from their position of stable equilibrium, no matter which might be the angle of stronger stimulation, or stronger response under fairer conditions. One may question, too, whether the arbitrary selection of twenty-four hours as the period for the measurement of angles is likely to lead to reliable conclusions.

With these thoughts in mind, but principally because stems had been insufficiently tested, Miss Haynes, in this laboratory, was assigned the subject of the angle of inclination of stems showing the strongest geotropic curvature, the test to be made by the method of alternate stimulation for a period less than the latent period, at angles of $90^{\circ}$ and $I 35^{\circ}$ from the position of stable equilibrium.

This method of alternate or rhythmic stimulation on opposite sides of a plant member was used by F. Darwin and Pertz ${ }^{2}$ in $\mathrm{I} 892$. It has since been used in a modified way by various authors, among them Czapek ${ }^{3}$,

1 'Geotropic Experiments.' Bot. Gazette, xxix, I900, p. I36. Abstract of paper read before Soc. Plant Morph. and Physiol., Dec., 1899.

2 'On the Artificial Production of Rhythm in Plants.' Annals of Bot., vi, 1892, p. 245.

${ }^{3}$ Ueber die Richtungsursachen der Seitenwurzeln und einiger anderer plagiotroper Pflanzentheile. Sitzungsber. d. k. Akad. d. Wiss., Math.-Naturw. Cl., civ, I. Abt., I895, p. I 197 . 
who employed it to determine the angle of inclination for maximum geotropic response of lateral roots. This method seems to me wholly free from objection. The plants are subjected for equal periods of time to gravitation stimulation, first on one side, then on the other, till by a summation of stimulations they curve. The direction of the curve, provided the great majority of plants behave alike, can be nothing less than an index of stronger geotropic stimulation or response.

By this method, Miss Haynes, whose work is soon to be published, tested the stems, young and old, of ten to twelve species, and found all of them to curve in response to the horizontal position. It occurred to me that primary roots ought to be tested in the same way also, inasmuch as this method had not been used with them. The following pages contain a record of this and other tests with a discussion of the results.

\section{Experimentation AND Discussion.}

I. Determination of the angle for maximum response by the method of perception-period.

This method is not quite the same as that of the latent period discarded by Czapek ${ }^{1}$, because he found the curves in roots beginning in about the same time when the angle of inclination was anywhere between $20^{\circ}$ and $160^{\circ}$ from the position of stable equilibrium. I have varied the method somewhat by exposing in each experiment two pots of seedlings of the same age for the same time, but less than the latent period, one at $90^{\circ}$ and the other at $\mathrm{I} 35^{\circ}$ from the position of stable equilibrium ; revolving them subsequently so as to neutralize gravitation, and observing the number of curvatures and the relative amplitude of the angles. In this series only the hypocotyls were used. The experiments were conducted in a dark room, at a temperature of $22^{\circ} \mathrm{C}$.

The first seedlings used were Brassica alba, L. Their latent period at $22^{\circ}$ was found to be $20 \mathrm{~min}$. for the earliest curve observed, while most of the stems showed no curves after $33 \mathrm{~min}$. A pot with eight seedlings was turned horizontally, and another with fifteen seedlings was turned with the stems pointing $45^{\circ}$ below the horizontal, both remaining in these positions for $33 \mathrm{~min}$. The pot at $90^{\circ}$ then showed three stems curved, while the one with stems $135^{\circ}$ from the position of stable equilibrium showed but one curved. After I 5 minutes' revolution on the klinostat in the vertical plane of curvature, six of the eight stems stimulated at $90^{\circ}$, and ten of the fifteen stimulated at $135^{\circ}$ showed geotropic curves. In each set three stems had attained an angle of $45^{\circ}$.

In all the other experiments with the hypocotyls of Brassica alba the period of stimulation was less than the latent period, being in some cases I $7 \frac{1}{2} \mathrm{~min}$. and in others $20 \mathrm{~min}$. Records were made at several times during the revolution, but the period of $30 \mathrm{~min}$. seemed to be the best one

${ }^{1}$ Untersuchungen über Geotropismus. Jahrb. f. wiss. Bot., xxvii, I895, p. 283. 
and the fairest one, and that is given here. The total number of hypocotyls stimulated at $90^{\circ}$ was forty-one, and the same number was stimulated at I $35^{\circ}$ from the position of stable equilibrium. After the stimulation for $17 \frac{1}{2} \mathrm{~min}$., or for $20 \mathrm{~min}$., and the subsequent rotation on the klinostat for $30 \mathrm{~min}$., twenty-four geotropic curves were observed in those exposed at $90^{\circ}$, and thirteen curves in those exposed at $\mathrm{I} 35^{\circ}$. In only one of the five experiments did the number of curves in the seedlings stimulated at $135^{\circ}$ equal those in the seedlings stimulated at $90^{\circ}$; and that was in the last experiment, where each pot of seven seedlings showed only one curve. In amplitude of angle the curves formed in response to the stimulation at $90^{\circ}$ were certainly the larger on the average; but there was a great deal of individual variation, and the evidence in this direction was not very strong, though more careful measurements might lead to stronger evidence.

Two pots of seedlings of Raphamus sativus, L., were used in the same way as the foregoing Brassica seedlings. The latent period at $22^{\circ} \mathrm{C}$. was found to be $25 \mathrm{~min}$. for the first stems to curve. In one pot, eighteen hypocotyls were stimulated in the horizontal position; while in the other, seventeen were placed $\mathrm{I} 35^{\circ}$ from their position of stable equilibrium. After lying $20 \mathrm{~min}$. in these positions, and then revolving for $40 \mathrm{~min}$. on the klinostat, each pot showed eleven hypocotyls curved geotropically. After revolving on the klinostat for $60 \mathrm{~min}$, eleven of the eighteen stimulated at $90^{\circ}$ were curved, while seven of those stimulated at $135^{\circ}$ were curved.

The same seedlings just described were allowed to stand for I hour and $30 \mathrm{~min}$. and were used again as before. Stimulation was for I $5 \mathrm{~min}$. only; the seedlings that were laid at $90^{\circ}$ before now being placed at $135^{\circ}$, and those before at $135^{\circ}$ now being at $90^{\circ}$. The largest number of curves in each pot came after $45 \mathrm{~min}$. of revolution on the klinostat; then those seedlings stimulated at $90^{\circ}$ showed four curves, those at $\mathrm{I} 35^{\circ}$ one curve. Subsequently all the hypocotyls began to straighten.

The foregoing results cannot be said to furnish conclusive evidence for either the position at $90^{\circ}$ or that at $135^{\circ}$ as giving the stronger geotropic response. The indications, however, point to the horizontal position as the more effective, since the larger number of curves and the larger angles came in response to that position.

2. Determination of the angle for maximum response by the method of alternate stimulation.

Alternation at $90^{\circ}$ and $\mathrm{I} 35^{\circ}$.- To facilitate this alternate stimulation there was constructed a device consisting of a heavy board base, rising about a foot, to the top of which was hinged a board capable of a rotation of $135^{\circ}$ about a horizontal axis. . The base and hinged board were 5 feet in length, thus giving room for several plant pots or damp chambers at one time. The hinged board was pierced by holes to receive the small plant crocks, and was provided with hooks and wires to allow ready means of securing 
the pots or damp chambers in place. The base itself had two faces at right angles to one another, upon either one of which it could lie on the table. The plants could thus stand in their normally erect position while they were being secured to the hinged board, and then, when all the containers were secured, the whole apparatus could be turned through $90^{\circ}$, and all the plants put at the same inclination at the same instant.

All the experiments were made in the dark room the temperature of which ranged from $20^{\circ}$ to $24^{\circ} \mathrm{C}$. The alternating process continued till several to many curves had appeared, but not always long enough to bring curves in all the plants. The period varied from 4 hours for Brassica, Raphamus, and Lupinus, to Io hours for Vicia Faba and Zea Mays. The results were so generally uniform and decisive that details of individual species and experiments may be omitted, and the whole given in tabular form. The stimulation was usually begun with the plants inclined $135^{\circ}$ from their position of stable equilibrium. This would give this position a slight advantage over the $90^{\circ}$ position. The plants remained in each position I 5 min. It required about I second to change from one position to the other. In changing from one position to the other, the plants always passed across the vertical plane, thus bringing alternately the opposite sides of the plants toward the earth.

TABLE I.

Showing results of stimulation alternately at $\mathrm{I} 35^{\circ}$ and $90^{\circ}$ from the position of equilibrium.

\begin{tabular}{|c|c|c|c|c|}
\hline Plants. & $\begin{array}{c}\text { Total } \\
\text { number. }\end{array}$ & $\begin{array}{l}\text { Curves } \\
\text { caused } \\
\text { by } 90^{\circ} \text {. }\end{array}$ & $\begin{array}{c}\text { No } \\
\text { curves. }\end{array}$ & $\begin{array}{l}\text { Curves } \\
\text { caused } \\
\text { by } \mathrm{I} 35^{\circ} \text {. }\end{array}$ \\
\hline $\begin{array}{l}\text { Brassica alba, hypocotyl } \\
\text { Raphanus sativus, ", } \\
\text { Helianthus annus, " } \\
\text { Vicia Faba } \\
\text { Zea Mays, coleoptile" } \\
\text { (White dent) }\end{array}$ & $\begin{array}{r}76 \\
69 \\
27 \\
5 \\
14\end{array}$ & $\begin{array}{r}50 \\
47 \\
18 \\
4 \\
14\end{array}$ & $\begin{array}{r}26 \\
\text { I9 } \\
8 \\
0 \\
0\end{array}$ & $\begin{array}{l}0 \\
3 \\
1 \\
\text { I } \\
0\end{array}$ \\
\hline Total stems & I9I & I 33 & 53 & 5 \\
\hline $\begin{array}{l}\text { Brassica alba, primary root } \\
\text { Raphanus sativus, ", ", } \\
\text { Helianthus annuus, ," ", } \\
\text { Lupinus albus, ", ", } \\
\text { Vicia Faba, ", ", } \\
\text { Zea Mays, } \\
\text { (White dent) ", ", }\end{array}$ & $\begin{array}{r}\text { I9 } \\
\text { 19 } \\
5 \\
\text { I } 2 \\
8 \\
8 \\
\text { I } 4\end{array}$ & $\begin{array}{r}\text { I } 3 \\
10 \\
5 \\
\text { I } 2 \\
4 \\
9\end{array}$ & $\begin{array}{l}4 \\
8 \\
0 \\
0 \\
3 \\
4\end{array}$ & $\begin{array}{l}2 \\
\text { I } \\
0 \\
0 \\
\text { I } \\
\text { I }\end{array}$ \\
\hline Total roots & 77 & 53 & I9 & 5 \\
\hline
\end{tabular}

The results are capable of easy demonstration. Let any one who wishes make the test with Helianthus annuus for stems and roots, or with Lupinus albus for roots. Vicia Faba and Zea Mays (except for the 
coleoptile) are among the most insensitive and aberrant of plants commonly worked with. These two species have played leading rôles in plant physiology far too long. With them one must continue the foregoing experiment twice as long as for the other species used.

The results shown in the preceding table are decisive. They show the need of a critical examination of the method and results of Czapek by which he inferred a stronger response at $135^{\circ}$ than at $90^{\circ}$. We have the alternative on the one hand of regarding Czapek's method or the one employed here as faulty, or on the other of supposing that different tests, all fair, will lead to different conclusions as to the angle of inclination bringing the strongest geotropic response. On a later page of this paper evidence will be offered which is believed to indicate that the discrepancy in results by the two methods is due to the unreliability of one. It is difficult to see how the method used in this paper can be called unreliable. It is the method used by Czapek $^{1}$ himself to determine the inclination at which lateral roots give their strongest geotropic response. The number of stems and roots shown in the tables as remaining straight are of importance only in indicating that the experiments were not continued long enough to bring curves in all cases, and that there is considerable variation.

Alternation at $90^{\circ}$ and $\mathrm{II} 2.5^{\circ}$. - If we accept the foregoing experimental proof of a stronger geotropic response at an inclination of $90^{\circ}$ than at I $35^{\circ}$, we have still to determine whether the horizontal position is the one giving the strongest response. The following table shows the results obtained with a few seedlings alternated from $90^{\circ}$ to II $2.5^{\circ}$, conditions being the same as for the preceding series of experiments. The curves did not show till 8 to to hours after beginning the experiment.

TABLE II.

Showing results of stimulation alternately at $112.5^{\circ}$ and $90^{\circ}$ from the position of equilibrium.

\begin{tabular}{|c|c|c|c|c|}
\hline Plants. & $\begin{array}{c}\text { Total } \\
\text { number. }\end{array}$ & $\begin{array}{l}\text { Curves } \\
\text { caused } \\
\text { by } 90^{\circ} \text {. }\end{array}$ & $\begin{array}{l}\text { No } \\
\text { curves. }\end{array}$ & $\begin{array}{l}\text { Curves } \\
\text { caused by } \\
\text { I } 2.5^{\circ} \text {. }\end{array}$ \\
\hline $\begin{array}{l}\text { Brassica alba, hypocotyl } \\
\text { Helianthus annuus, ," } \\
\text { Zea Mays, coleoptile" } \\
\text { (White dent) }\end{array}$ & $\begin{array}{l}5 \\
7 \\
6\end{array}$ & $\begin{array}{l}5 \\
6 \\
6\end{array}$ & $\begin{array}{l}0 \\
\text { I } \\
0\end{array}$ & $\begin{array}{l}\circ \\
\circ \\
\circ\end{array}$ \\
\hline Total stems & I 8 & 17 & I & 0 \\
\hline $\begin{array}{l}\text { Lupinus albus, primary root } \\
\text { Helianthus annuus, ", " }\end{array}$ & $\begin{array}{r}10 \\
2\end{array}$ & $\begin{array}{l}9 \\
2\end{array}$ & $\begin{array}{l}\text { I } \\
\text { o }\end{array}$ & $\begin{array}{l}\circ \\
\circ\end{array}$ \\
\hline Total roots & I 2 & II & I & o \\
\hline
\end{tabular}

${ }_{1}^{1}$ Ueber die Richtungsursachen der Seitenwurzeln etc. Sitzungsber. d. k. Akad. d. Wiss., Math.Naturw. Cl., civ, I. Abt., I895, p. I216. 
Alternation at $90^{\circ}$ and $100^{\circ}$.- In this test the curves in the roots of Lupinus albus came more slowly than in those of the preceding experiment, though the temperature here was $24^{\circ}$ and there $22.5^{\circ}$. This would indicate that the stimulations on the opposite sides of the roots were more nearly equal. The result shows unmistakably that the position at $90^{\circ}$ gives a stronger effect than at $100^{\circ}$. The plants were placed first in the position with their axes inclined $100^{\circ}$ from the position of stable equilibrium, thus giving probably a slight advantage to the stimulation in that position. The alternation was made every I $5 \mathrm{~min}$. for 12 hours. Ten seedlings of Lupinus albus, about $6 \mathrm{~cm}$. long, in damp chambers showed six root-tips bent slightly in response to stimulation at $90^{\circ}$, one apparently in response to $100^{\circ}$, and the other three roots straight. In a pot of twelve seedlings of Brassica alba, seven hypocotyls ben in response to the position at $90^{\circ}$, one apparently in response to $100^{\circ}$, and the other four grew straight. In a pot of eleven seedlings of Raphamus sativus, seven hypocotyls bent in response to the position at $90^{\circ}$, and the other four grew straight.

Alternation at $90^{\circ}$ and $67.5^{\circ}$.-For this test seedlings of Lupinus albus and of Helianthus annuus were used on the alternating rack. The former were in damp chambers, and were observed for the behaviour of roots; the latter grew in pots of sawdust, and only their hypocotyls were studied. After the alternating process had been continued for eight hours at a temperature of $23^{\circ}$, all of the twelve Lupinus roots were curved in response to the position at $90^{\circ}$; while of the fifteen hypocotyls of Helianthus, twelve had bent in response to the position at $90^{\circ}$, and the other three remained straight.

Alternation at $90^{\circ}$ and $45^{\circ}$.- Only one set of seedlings was tested at these angles-the primary roots of Lupinus albus. After the alternation had been continued for 5 hours in temperature $22.5^{\circ}$, eight of the twelve roots showed curves in response to the position of $90^{\circ}$; the other four roots remained straight. In this set of seedlings the hypocotyls were too short for good results and were not observed.

The position at $90^{\circ}$ stimulates to bending more strongly than at $45^{\circ}$, $67.5^{\circ}, 100^{\circ}$, II $2.5^{\circ}$, or $135^{\circ}$. From this we may infer that the position of strongest geotropic stimulation or response is $90^{\circ}$ from the position of normal equilibrium.

3. Determination of the angle for maximum response by the method of the after-effect.

Under the foregoing heading I have placed several experiments conducted after the manner of those of Czapek. Good seedlings were selected for the test, the glass tubes were shaped to fit the root-tips closely, and the revolution on the klinostat began immediately on the removal of the glass tubes. The tubes were washed thoroughly before using, were 
about one centimetre in length, and were open at both ends, the tapering end having but a small pore, and the growing root pushing the glass tube forward. The glass tubes were placed over the root-tips, and the roots, always in two sets, laid the one set at $90^{\circ}$ the other at $135^{\circ}$ from the position of stable equilibrium. The glass tubes lay on a plane support below, so that their weight did not rest on the roots. The seedlings were so placed that during revolution when the curves came the curves were parallel with the vertical plate of the klinostat. The following table is so constructed as to show changes in the angles of roots as the experiment progressed, and to show variation among the members of the same set of seedlings. The third column shows the period of stimulation while the roots were covered with glass tubes. The fourth column gives the time of observation after the glass tubes were removed. The fifth and seventh columns show the position of individual roots at two or three periods during the experiment; all of the numbers in the same vertical row in any one experiment give the angles for the same root. The sixth and eighth columns give the average angles at the observation nearest 24 hours. The four numbers marked ' $*$ ' indicate original angles reversed. The angles as given are all for the place of the original curvature. The subsequent curves nearer the apex of the roots are not indicated.

An inspection of the following table shows such an individual variation on the part of the roots that the whole method must appear unsatisfactory. It is true that three of the four experiments give average results favouring the position of $135^{\circ}$; but the fourth experiment reverses this result. Moreover, in each experiment of five roots there are at least two roots from the position of $90^{\circ}$ that, after many hours' rotation, exceed in their angles the two smallest from $I 35^{\circ}$. As worthy of note in the behaviour not shown in the table it may be said that roots kept in the forced positions in glass tubes usually tend to reduce their original angles after a few hours' stay on the klinostat, and even continue to reduce the angles after the apex of the angle has passed beyond the region of the so-called elongating zone. In the last experiment, for example, given in the table, several of the roottips after 20 hours were $15 \mathrm{~mm}$. beyond the angles; yet the angles were reduced during the ensuing 16 hours. 
TABLE III.

Showing angles attained on the klinostat after prolonged forced stimulation.

\begin{tabular}{|c|c|c|c|c|c|c|c|}
\hline \multirow{2}{*}{ Species. } & \multirow{2}{*}{$\begin{array}{l}\text { Tempera } \\
\text { ture. }\end{array}$} & \multirow{2}{*}{$\begin{array}{c}\text { Period of } \\
\text { stimulation. }\end{array}$} & \multirow{2}{*}{$\begin{array}{l}\text { Time of } \\
\text { observa- } \\
\text { tion. }\end{array}$} & \multicolumn{4}{|c|}{ Angles attained. } \\
\hline & & & & From $90^{\circ}$. & $A v$. & From $135^{\circ}$. & $A v$. \\
\hline $\begin{array}{l}\text { Vicia } \\
\text { Faba }\end{array}$ & $22^{\circ}$ & $5 \mathrm{hrs}$. & $\begin{array}{l}30 \mathrm{~min} . \\
25 \frac{\mathrm{I}}{2} \mathrm{hrs} .\end{array}$ & $\begin{array}{l}90,9 \circ, 3 \circ, 9 \circ, 9 \circ, 60 \\
45,3 \circ, 45,12,5^{\circ}, \text { I } 5\end{array}$ & 33 & $\begin{array}{l}9 \circ, 45,70,9 \circ, 9 \circ \\
4^{\circ}, 5 \circ, 35,80,95\end{array}$ & 60 \\
\hline $\begin{array}{l}2 c 2 a \\
F a b a\end{array}$ & $26^{\circ}$ & 5 hrs. & $\begin{array}{l}5 \text { min. } \\
\text { I } 9 \text { hrs. } \\
24 \text { hrs. }\end{array}$ & $\begin{array}{l}40,30,30,0,30 \\
\text { I5, 0, I5, -1 } 5^{*}, \mathrm{I} 5 \\
\text { I5, 0, 0, -1 } 5^{*}, \mathrm{I0}\end{array}$ & 5 & $\begin{array}{l}45,20,45,15,5^{\circ} \\
3 \circ, 30,30,0,-25^{*} \\
30,30,30,0,-10^{*}\end{array}$ & 18 \\
\hline $\begin{array}{l}\text { Lupinus } \\
\text { albus }\end{array}$ & $23.5^{\circ}$ & $4 \mathrm{hrs}$. & $\begin{array}{l}\text { Io min. } \\
\text { I } 2 \text { hrs. } \\
24 \text { hrs. }\end{array}$ & $\begin{array}{l}\circ, 70,70,80,60 \\
\circ, 30,30,15,20 \\
0,30,3 \circ, 0,0\end{array}$ & 12 & $\begin{array}{l}45,30,45, \text { o, } 45 \\
55,40,30, \text { I } 5,55 \\
45,45,30,0,45\end{array}$ & 33 \\
\hline albus & $23^{\circ}$ & $4 \frac{1}{2} \mathrm{hrs}$. & $\begin{array}{l}25 \mathrm{~min} . \\
20 \mathrm{hrs} . \\
36 \text { hrs. }\end{array}$ & $\begin{array}{l}30,30,45,60,60 \\
30,30,0,60,40 \\
\text { I5, 10, 0, 10, } 10\end{array}$ & 34 & $\begin{array}{l}60,60, \text { Io, } 10,45 \\
75, \text { I0, o, o, } 45 \\
45, \text { o, o, o, I5 }\end{array}$ & 26 \\
\hline
\end{tabular}

In the experiments made by Czapek there are no details given from which we can judge of the similarity of behaviour of his primary roots. From the few like tests recorded in the present paper we may, however, infer that Czapek's results were correspondingly irregular.

\section{B. Relative Intensity of Response at Equal Angles ABOVE AND BELOW THE HORIZONTAL.}

When Sachs ${ }^{1}$ and Stone ${ }^{2}$ state that the geotropic response of primary roots and stems is approximately proportional to the cosine of the angle of inclination during stimulation, the deduction is that equal angles of inclination above and below the horizontal will cause equal geotropic reactions. Czapek ${ }^{3}$ contests this conclusion, stating that for roots all angles of inclination above the horizontal cause stronger curvatures than equal angles below; while for stems all inclinations below cause stronger curves than equal angles above the horizontal. The method employed to obtain these results was, however, the objectionable one used to find the angle for greatest geotropic effect. The experiments giving the best evidence for Czapek's conclusion are to my mind those of Miss Pertz ${ }^{4}$ on

1 Ueber das Wachsthum der Haupt- und Nebenwurzeln. Arbeit. bot. Inst. Würzb., i, 1873, p. 454 .

3 ' Geotropic Experiments.' Bot. Gazette, xxix, I900, p. I36.

3 Untersuchung über Geotropismus. Jahrb. f. wiss. Bot., xxvii, 1895, p. 283.

4 'On the Gravitation Stimulus in Relation to Position.' Annals of Bot., xiii, I899, p. 620. 
grass stems. In these experiments the intermittent klinostat was used, exposing grass stems alternately for the same interval to various equal angles above and below the horizontal. In twenty-seven cases in the thirty-four the stems bent toward the horizontal axis of revolution, thus indicating that the positions below the horizontal caused a stronger response.

A year ago I carried out a limited number of experiments from which the inference was drawn that the conclusions of Sachs and of Stone were wrong, and that those of Czapek and Miss Pertz were right. A report of my results was made incidentally in a paper ${ }^{1}$ dealing with the limitations of the klinostat. At the same time Fitting ${ }^{2}$ published a paper merely mentioning results which induced him to support Sachs' view, that stimuli at equal angles above and below the horizontal are equal. Fitting's method seemed adequate, and on other points his results were the same as my own. I could not doubt the results shown by my plants, but I resolved to subject the apparatus I had had made to a critical examination. This examination showed faulty construction, as the result of which the two positions of alternate stimulation, instead of being always $180^{\circ}$ apart, were but $177^{\circ}$ apart, all of the shortening being on one side of the vertical plane. This regrettable error was corrected, and another series of experiments carried through as detailed in the following lines.

On the alternating rack.-This device was the same as that described in the first part of this paper. The plants were fastened to the hinged board, and the latter was alternated from one side of the vertical plane to the other, and stopped in positions such as to give the longitudinal axes of the plants in the two positions equal angles with the horizontal plane, in one position above, in the other below the horizontal. In all these experiments the plants were so placed as to serve as checks on any irregularities in the apparatus, some of the pots or damp chambers being reversed with respect to the others. Thus, for example, while, in one position of the alternating stimulation, some of the roots were $45^{\circ}$ above the horizontal, the neighbouring reversed container would have its roots at the same time $45^{\circ}$ below the horizontal.

Seedlings of Pisum sativum, to the number of thirty-eight, were employed for the behaviour of their primary roots when alternated at intervals of 10 minutes from $45^{\circ}$ above to $45^{\circ}$ below the horizontal. In the two experiments the duration was in one case 7 hours and in the other 9 hours, at a temperature of $23^{\circ}$. Eleven roots bent slightly as though responding to the position above the horizontal, three as though responding to the position below the horizontal, and the other twenty-four remained straight. Twelve seedling roots of Lupinus albus in a similar experiment

1 'Limitations of the Klinostat às an Instrument for Scientific Research.' Science, New Ser. xx, 1904, p. 376 .

${ }_{2}$ Geotropische Untersuchungen. Vorl. Mittheil. Ber. d. d. bot. Gesellsch., xxii, r904, p. ${ }_{3}^{6}$ r. 
showed, after 8 hours' alternation, four individuals curving as though responding to the position above the horizontal, two curving as though responding to the position below the horizontal, and the other six straight.

Three small potted plants of Fuchsia and three of Verbena were subjected to alternate stimulation, the stems of the former being respectively $45^{\circ}, 65^{\circ}$, and $70^{\circ}$ from the horizontal, while those of the Verbena were $35^{\circ}$, $45^{\circ}$, and $60^{\circ}$ from the horizontal. After 8 hours' alternate stimulation only one stem, a Verbena, curved, and that was in the direction as though responding to the position above the horizontal. At the end of the alternation the plants were laid upon their sides at rest to see whether they were in a sensitive condition. After an hour and a half four of the six stems had curved geotropically.

On the klinostat.-If stems and roots are not equally stimulated geotropically, at equal angles above and below the horizontal position, revolution on the klinostat with horizontal axis will, by summation of stimulation, cause curves. In making experiments to determine the question suggested, it is of the very first importance that the axis of the klinostat should be strictly horizontal, and the revolution should be uniform in every part of the course, since a very slight deviation in either direction will lead to erroneous conclusions.

The klinostats used in my experiments revolved within the limits of once in 4 minutes, and once in 12 minutes. The temperature ranged between $17^{\circ}$ and $25^{\circ}$, and the periods varied from 28 to 48 hours. A curve of a root toward the horizontal would indicate a stronger response from the position above the horizontal, while a curve away from the horizontal would indicate a stronger response from the position of the root inclined below the horizontal. Primary roots of Pisum sativum, to the number of nine, when adjusted $45^{\circ}$ from the horizontal, showed three bending toward the horizontal, one away, and five straight. Twelve hypocotyls of Raphamus sativus showed one bending toward the horizontal, two away, and nine straight. Four hypocotyls of Brassica alba all grew without curving. Eleven coleoptiles of $Z$ ea Mays bent variously, but without any orientation. Two stems of Fuchsia showed no curves.

These results certainly indicate that orthotropic roots and stems receive equal stimuli at equal angles above and below the horizontal. The curves which were formed in the foregoing experiments are regarded as autotropic, the plant having no external directive influence. The experimenter knows that in the absence of directive influences such devious curves are not rare. 


\section{SUMMARY.}

The present paper deals with two questions: (1) the angle of inclination of primary roots and stems at which the strongest geotropic reaction is effected; (2) the relative geotropic effect at equal angles of inclination above and below the horizontal plane.

It has been shown that evidence on these questions has been heretofore too meagre, principally on account of the insufficiency of method employed. One of the methods employed by Sachs to settle the first question-that of the determination of the latent period-has been found by several experimenters to be difficult to use because the latent period seems to be almost the same for all angles of inclination, except for very small angles. The method of the comparison of angles attained in a given time, when roots and stems are placed at various angles of inclination, is not satisfactory, because the angle of inclination begins to change as soon as the curve begins. The method of measuring the angles attained after releasing plant members forced to retain fixed angles of inclination during prolonged stimulation is objectionable theoretically; and, in practice, roots so treated are found to behave very irregularly.

In the present paper the method of alternate, intermittent stimulation has been most employed, and, in addition, the method of determining the perception period at $90^{\circ}$ and $135^{\circ}$ from the position of stable equilibrium, by stimulating for a time less than the latent period and then rotating the plant on the klinostat.

The tests made by determining the perception period of the hypocotyls of Brassica alba and Raphanus sativus were not very decisive, since there is considerable irregularity of results ; but the weight of evidence indicated the position at $90^{\circ}$ as having a shorter perception period than at $135^{\circ}$.

The experiments by alternate stimulation on opposite sides of the same plant member for equal periods of time, but at different angles, leave no ambiguity. All of the five species of plants used showed their seedling stems responding to the position at $90^{\circ}$ rather than to that at $135^{\circ}$, or any other angle from the position of stable equilibrium; and all of the six species of plants used showed the same reaction with their primary roots.

The experiments made to determine whether the geotropic effect is the same on plant members at equal distance above and below the horizontal were less uniform. By alternating plants every 15 minutes from a position above the horizontal plane on one side of the vertical plane to a position an equal distance below the horizontal on the other side of the vertical plane, the ensuing curvature after some hours would indicate which position was most influenced by the gravitation stimulus. It was found that for both roots and stems there were irregular curves, but that the large majority grew straight. 
The whole matter of the inclination at which roots and stems show their strongest geotropic response is brought to this condition, as shown principally by the method of alternate stimulation:-

The orthotropic stems of plants receive their maximum gravitation stimulation at an angle of $90^{\circ}$ from their position of stable equilibrium. This is shown by every one of the five species of seedlings used in the present paper, and by some ten species of plants with older stems, as will soon be shown by the publication of other work from this laboratory.

The orthotropic roots of plants receive their maximum gravitation stimulation at an angle of $90^{\circ}$ from their position of stable equilibrium, as shown by every one of the six species of seedlings alternately stimulated, as recorded in this paper.

The lateral roots of plants Czapek found by the method of alternate stimulation to receive their maximum gravitation stimulation at $60^{\circ}$ to $90^{\circ}$ above their position of stable equilibrium.

Orthotropic roots and stems of plants, as shown in the present paper, receive equal gravitation stimulation at equal angles above and below the horizontal.

Lateral roots, as found by Czapek, curve more readily when displaced above their position of stable equilibrium than at equal distances below. 


\section{$2 \mathrm{BHL}$ Biodiversity Heritage Library}

Newcombe, Frederick C . 1905. "Geotropic response at various angles of inclination." Annals of botany 19, 311-323.

https://doi.org/10.1093/oxfordjournals.aob.a089002.

View This Item Online: https://www.biodiversitylibrary.org/item/233541

DOI: https://doi.org/10.1093/oxfordjournals.aob.a089002

Permalink: https://www.biodiversitylibrary.org/partpdf/318800

\section{Holding Institution}

Smithsonian Libraries

\section{Sponsored by}

Biodiversity Heritage Library

\section{Copyright \& Reuse}

Copyright Status: Not in copyright. The BHL knows of no copyright restrictions on this item.

This document was created from content at the Biodiversity Heritage Library, the world's largest open access digital library for biodiversity literature and archives. Visit BHL at https://www.biodiversitylibrary.org. 